\title{
Repository 2.0: Social Dynamics to Support Community Building in Learning Object Repositories
}

\author{
Sergio Monge, Ramón Ovelar, and Iker Azpeitia \\ University of the Basque Country, Spain \\ sergio.monge@ehu.es, ramon.ovelar@gmail.com, \\ iker.azpeitia@ehu.es
}

\begin{abstract}
Learning Object Repositories constitute a comprehensive strategy to support ICT use in educational contexts. From this perspective, user participation in repository services is a desirable objective. We propose a contribution model that makes it possible to analyze the openness of these services in a repository. We also make a proposal of six Web 2.0 strategies to be used to encourage social dynamics and participation around a repository.
\end{abstract}

Keywords: repository, learning objects, open educational resources, participation, Web 2.0, recommendation, reputation, social tagging

\section{Introduction}

A digital repository is a system that "enables the storage, discovery and retrieval of metadata and/or electronic objects stored at a local or distributed level" (The JORUM Team, 2006, p. 8). More specifically, a learning object repository (LOR) is a system that manages the access to reusable learning content, as it has been defined by several authors (Downes, 2004; López 2005; Namuth, Fritz, King, \& Boren, 2005). However, the bounds of what can be called a LOR remain blurred as there is no common agreement about the nature of learning objects themselves (McGreal, 2004; Wiley, 2001). Some of their main features (such as granularity, metadata, and interoperability) cannot be found in the items of repositories listed in different LOR repertories such as LIFE (2006) or McGreal (2007). For the purposes of this paper, we will adopt an inclusive vision, as we are focusing on user engagement issues that can be applied to any repository or portal storing learning resources.

Access to learning resources relies on technical and economic matters that are being considered within the Open Educational Resources (OER) approach. Although there is not an authoritatively accredited definition (Geser, 2007), we can assume that OER consists of educational content and

Material published as part of this publication, either on-line or in print, is copyrighted by the Informing Science Institute. Permission to make digital or paper copy of part or all of these works for personal or classroom use is granted without fee provided that the copies are not made or distributed for profit or commercial advantage AND that copies 1) bear this notice in full and 2) give the full citation on the first page. It is permissible to abstract these works so long as credit is given. To copy in all other cases or to republish or to post on a server or to redistribute to lists requires specific permission and payment of a fee. Contact Publisher@InformingScience.org to request redistribution permission. resources - including software - that can be accessed free of charge and can be reused and modified. Open licenses which allow users to access resources and adapt them to their particular needs are relevant as they do not envisage the mere retrieval of content but also active work on it.

LORs have been created and maintained by many educational administrations 
and institutions (LIFE, 2006) because the provision of learning resources is essential for the development of ICT in education. From this perspective, design and policies contributing to the engagement and participation of the educational community will improve the uptake of these systems. Integrating Web 2.0 technologies (O'Reilly, 2005) can be very useful for this purpose.

The CDLOR project has researched the barriers and enablers that influence implementation and use of LOR and recommends that these systems "be based firmly on the needs and context of the end user communities" they aim to serve (Margaryan, Milligan, Douglas, Littlejohn, \& Nicol, 2007 , p. 5). Other recommendations include considering the LOR role "in supporting collaboration on development of resources ... rather than only being used to store completed resources" and the addition of Web 2.0 features allowing "collaboration, communication, feedback, and other forms of social networking activities around the resources; for example, recommendation mechanisms and user feedback functionalities...".

Franklin and Van Harmelen (2007, p. 16) consider that repositories could become more accessible "for learning and teaching through the use of Web 2.0 technologies, including tagging, folksonomies and social software", although the introduction of these features might raise discussions as to who may see and modify other users' content. While comments, recommendations, tags, or ratings are more easily integrated, collaboration in the core of content, as occurs with wikis, is more challenging.

Based on an OER approach, the OLCOS Roadmap 2012 (Geser, 2007, p. 126) emphasizes that a bottom-down strategy, where repository users are not considered "as consumers but as potential co-creators of shared, commons-based resources" will benefit innovation in teaching and learning. In order to promote and motivate contributions, what the report recommends is "to consider more thoroughly how tools and services can make it beneficial for content creators and providers to make use of the repository", adding features for managing content and content licenses, collaborative tools for communities, alerts, RSS feeds, etc.

This paper explores the possibilities of leveraging the uptake of learning object repositories integrating Web 2.0 technologies in order to enhance user engagement in these systems. To this end, in the next section we propose a classification of user roles and compare roles and rights in different repository systems, identifying features that can help to evaluate the degree of openness of a repository's contribution model. We will then focus on the analysis of a specific net of federated repositories that will provide learning content covering the curriculum of pre-university education - one of the goals of the Spanish ICT development plan "Internet en el aula". In the section following that, we propose the implementation of six well-known Web 2.0 strategies and technologies in order to encourage social dynamics within repositories' communities.

\section{Open or Editorial Contribution Models}

Besides the provision of learning resources and powerful and intuitive search features, repositories can fulfill a role in the development of ICT in the field of education through the emergence of active communities of users. In order to fully understand issues concerning the engagement of users, we need to analyze their rights within the system: how they are organized in role categories and how they can interact with the system and with other users of the system.

As a first step we have established four categories of users according to the way they acquire their roles:

- Non registered users: they access the system without any login and the only way to record their actions is to relate them to an IP number. 
- Open registration: users create an account through an automatic validation process, normally filling out a form where they have to provide a valid email address or some other anti-spam method.

- Controlled registration: to obtain this role users have to fulfill a specific requirement, sometimes having an institutional email address, sometimes through a human-controlled validation. For instance, some repositories offer special contribution rights to teachers or content production companies.

- Repository administrators: apart from being responsible for running the system, in a traditional contribution model they are the unique providers of the resources.

As long as non-registered users or users registered through an open process can make contributions that are visible to other users, a system has an open contribution model. Meanwhile, in a traditional contribution model administrators are responsible for the content, and we will refer to this as an editorial model.

Open contribution models such as Wikipedia's (http://www.wikipedia.org), where non-registered users can edit articles, are not frequent in repositories. For instance, at Connexions (http://cnx.org), one of the most relevant examples of LOR having an open contribution model, authors cannot be anonymous. This requirement constitutes a motivation for the author, since $\mathrm{s} / \mathrm{he}$ obtains recognition, while at the same time it permits users to select materials in accordance with the source they desire. Furthermore, the assurance of quality standards, either for content or metadata, when dealing with user generated content in a repository is challenging (Thomas \& Rothery, 2005).

Another important aspect is the nature of contribution. The idea behind the " $1 \%$ rule" is based on the fact that, in social software sites, only a small percentage of users make really major contributions, such as uploading a video to YouTube (http://www.youtube.com). Another $10 \%$ of users interact with the content (rates, tags, recommendations, etc.) while the rest of users will only read or retrieve documents (Arthur, 2006). Consequently, on the one hand, we will analyze the rights of users for contributing content, and on the other, the rights for making other actions, such as adding metadata, reviews, rating or tags, having a public profile, or sharing content with other users. The social dimension of these last features, which we describe as "minor contributions" in comparison with the authorship of learning resources - the so-called "major contributions" - is important to repositories because it represents a chance for more participation.

In the next sections, we will analyze user roles and rights for a non-exhaustive list of repositories. Table 1 shows several aspects of the way users can interact with the system, with the content and with other users.

\begin{tabular}{|c|c|c|c|c|c|c|c|c|}
\hline \multicolumn{7}{|c|}{ Table 1: User registration } \\
\hline User role & Connexions & $\begin{array}{c}\text { OER } \\
\text { Commons }\end{array}$ & $\begin{array}{c}\text { Curriculum } \\
\text { Online }\end{array}$ & TEEM & Respel & Skoolie & IDEAS & PrimTICE \\
\hline $\begin{array}{c}\text { Non- } \\
\text { registered } \\
\text { users }\end{array}$ & & & & & & & & \\
\hline $\begin{array}{c}\text { Open reg- } \\
\text { istration }\end{array}$ & - & $\bullet$ & & & & & & \\
\hline $\begin{array}{c}\text { Controlled } \\
\text { registration }\end{array}$ & & $\bullet$ & $\bullet$ & $\bullet$ & $\bullet$ & & $\bullet$ & \\
\hline $\begin{array}{c}\text { Repository } \\
\text { administra- } \\
\text { tors }\end{array}$ & & & & & $\bullet$ & $\bullet$ & $\bullet$ & \\
\hline
\end{tabular}




\section{Content Contribution Model}

Looking at Table 1 we can see four groups. At Connexions and OER Commons (http://www.oercommons.org), two repositories whose policies and design rely on the idea of Open Education Resources, any registered user can make contributions, even if for the latter example the vast majority of content is the result of gathering other existing collections promoted by institutions. At Curriculum Online (http://www.curriculumonline.gov.uk/), a repository providing free and commercial resources, as well as at TEEM (http://www.teem.org.uk/), where all the materials are commercial, only companies and institutions that have been approved previously can contribute resources. Finally, at IDEAS (http://www.ideas.wisconsin.edu/), RESPEL (http://www.enseignement.be/respel/), PRIMTICE (http://primtice.education.fr/) and Skoolie (http://www.skoool.ie/), resources are selected by administrators. In the first two examples users can send private messages to administrators with suggestions.

\begin{tabular}{|c|c|c|c|c|c|c|c|c|}
\hline \multicolumn{9}{|c|}{ Table 2: Free or commercial content } \\
\hline & Connexions & $\begin{array}{c}\text { OER } \\
\text { Commons }\end{array}$ & $\begin{array}{c}\text { Curriculum } \\
\text { Online }\end{array}$ & TEEM & Respel & Skoolie & IDEAS & PrimTICE \\
\hline Free content & $\bullet$ & $\bullet$ & $\bullet$ & & • & $\bullet$ & $\bullet$ & • \\
\hline $\begin{array}{c}\text { Commercial } \\
\text { content }\end{array}$ & & & $\bullet$ & $\bullet$ & & & & \\
\hline
\end{tabular}

Licenses are also a key feature for content stored in repositories. Apart from being free or commercial (see Table 2), there are other important questions, such as whether attribution is mandatory for using the resource or whether modification and adaptation is allowed. Contributors to Connexions and OER Commons have to choose a Creative Commons license for their content, where the aforementioned issues are regulated. Other systems such as IDEAS, RESPEL, PRIMTICE, and Skoolie select learning content that are available on the Internet and the license therefore depends on the source and is not always established. At TEEM and Curriculum Online license depends on the provider's choice.

\section{Contribution Model of Metadata and Other Information Concerning the Resource}

Contribution models for metadata are summarized in Table 3. In the majority of the examples analyzed, the metadata provision process is carried out by administrators (GU4). In other cases, authors are responsible for metadata and, in accordance with the contribution model, they belong to controlled registration users (GU3) or registered users (GU2). In addition, companies and organizations providing content to Curriculum Online and TEEM can demand, at their own expense, an independent review of their materials (GU3). 
Table 3: Contribution model of metadata and other information concerning the resource

GU1 Non-registered - GU2 Open registration - GU3 Controlled registration - GU4 Administrators

\begin{tabular}{|c|c|c|c|c|c|c|c|c|}
\hline & Connexions & $\begin{array}{c}\text { OER } \\
\text { Commons } \\
\end{array}$ & $\begin{array}{c}\text { Curriculum } \\
\text { Online }\end{array}$ & TEEM & Respel & Skoolie & IDEAS & PrimTICE \\
\hline Metadata & GU2* & GU2* & GU3* & & GU4 & GU4 & GU4 & GU4 \\
\hline Reviews & & GU2 & GU2, GU3 & GU3 & & & & \\
\hline $\begin{array}{l}\text { Discussion in } \\
\text { forums }\end{array}$ & GU1 & & & & & & & \\
\hline Ratings & GU4 & GU2 & & & & & & \\
\hline Folksonomies & & GU2 & GU3* & & & & & \\
\hline
\end{tabular}

We find that open contribution models are more frequently used for the provision of other information concerning resources, such as user reviews, ratings, or folksonomies. (A folksonomy is a user generated taxonomy used to categorize and retrieve content using open ended labels called tags.) OER Commons and Curriculum Online enable registered users (GU2) to make reviews of the materials they have utilized and every resource at Connexions has a forum open to any user (GU1). Nevertheless, none of these examples has achieved significant participation. On the other hand, contributions from open-registered users (GU2) such as tags (OER Commons) and ratings (Connexions, OER Commons, IDEAS) have obtained better outcomes. Also, resources at Connexions are ordered by a popularity index, although the criteria for setting the index are not public. IDEAS's users (GU1) can also send comments on the resources to the administrators but these messages are not public and do not, therefore, produce any information for other users.

\section{Personal and Social Tools}

Repositories also provide some tools that improve user experience. Personal folders, features that allow users to "bookmark" interesting items, are among the most frequently used tools within studied cases. In Curriculum Online, these lists of resources or educational contents and related information can be sent by mail. OER Commons users can publish their selections in their portfolio, a feature that in fact represents a recommender system that enables a sort of social information retrieval system.

Apart from that, we find some alert features through a newsletter (Curriculum Online) or RSS syndication (PrimTICE). IDEAS adds a personalization feature that allows their users to hide those sections that do not interest them. The ease of use of the authoring tools offered by Connexions, along with the openness of the system, is undoubtedly one of the reasons for its widespread adoption. Table 4 summarizes the tools that can be found in these repositories. 
Table 4: Personal and social tools

\begin{tabular}{|c|c|c|c|c|c|c|c|c|}
\hline & Connexions & $\begin{array}{c}\text { OER } \\
\text { Commons }\end{array}$ & $\begin{array}{c}\text { Curriculum } \\
\text { Online }\end{array}$ & TEEM & Respel & Skoolie & IDEAS & PrimTICE \\
\hline $\begin{array}{l}\text { Personal fol- } \\
\text { der }\end{array}$ & $\bullet$ & $\bullet$ & $\bullet$ & & & & $\bullet$ & \\
\hline $\begin{array}{l}\text { Profile - Port- } \\
\text { folio }\end{array}$ & & $\bullet$ & & & & & & \\
\hline Work group & $\bullet$ & $\bullet$ & & & & & & \\
\hline $\begin{array}{l}\text { Authoring } \\
\text { tool }\end{array}$ & $\bullet$ & & & & & & & \\
\hline $\begin{array}{l}\text { Module ag- } \\
\text { gregation }\end{array}$ & $\bullet$ & & & & & & & \\
\hline Newsletter & & & & $\bullet$ & $\bullet$ & & & $\bullet$ \\
\hline RSS feed & & & & & & & $\bullet$ & \\
\hline
\end{tabular}

\section{Dimensions of the "Internet en el Aula" Community}

One of the main goals of the Spanish ICT development plan "Internet en el Aula" (2005 - 2008) is to provide for "the educational community a wide collection of digital educational content, through a federated net of repositories that can be accessed from the autonomic regions educational portals and the Science and Education Ministry site" (Gertrudix, Álvarez, Galisteo, Gálvez, \& Gértrudix, 2007). Spain is divided into 17 autonomic regions. Although the Spanish Science and Education Ministry sets some global educational policies, most autonomic regions have their own educational administrations with a great deal of independence. The production, spreading, and evaluation of educational resources is considered as a global strategy for the development of ICT in the educational field and is included in the agenda of all administrations with competencies in Spanish education, from the autonomic regions to the Science and Education Ministry and the European Commission.

The educational community comprises all the agents (students, teachers, parent, etc.) involved in primary and secondary education. Moreover, this federated net of repositories will have a national scope and will attend the needs of a heterogeneous group of users: all curriculum subjects, different ages, different levels of computer literacy, different accessibility requirements, etc. The repository must help to promote the introduction of ICT and the reinforcement of regular teaching activities in primary and secondary education.

Concerning the contribution model of content, the design of the project plans for learning resources are to be exclusively provided by the educational administrations of the autonomic regions and the Science and Education Ministry. Resources will be shared within the federated net of repositories. Regarding the technical and economic aspect, learning content will be reusable and open. On the one hand, these resources will attend to the requirements of modularity, adaptability, reusability, interoperability, and portability; therefore, they can be considered as learning objects. On the other hand, they are defined as OER. The resources provided by "Internet en el Aula" will be available for all users on the Internet and will have an open license (Creative Commons Attribution, Non-Commercial - Share Alike), which will permit their extension, modification, and combination. The repository will be funded by national and autonomic regions educational administrations. 
These resources will be available through a federated net with 18 nodes, corresponding to the 17 autonomic regions and the Science and Education Ministry. A search and information retrieval system will enable the educational community to access a wide collection of learning objects, which will number approximately 5100 in the launching of the federated net of repositories in the second quarter of 2008 (Segura, Candioti, \& Medina ,2007; 19). As the system is a federated net of repositories, there are also relevant technical issues in the development of this plan. Analysis of the protocols that make it possible to link repositories (Friesen, 2006) goes beyond the focus of this paper, but it is evident that this characteristic, allowing users to enter the same content via different "gates", and the probable connection of this network with other European repositories, will affect the way users will interact with the systems and other users.

The repository must respect different teaching methodologies and different learning styles. The community of this repository lacks the "weak ties" (Granovetter, 1973) that are necessary to build a healthy social network. Teachers usually maintain "strong ties" with other teachers of their school, but lack the same ties with colleagues in other schools or even regions. The community of this national repository will comprise users from all the autonomic regions of Spain and that is why some virtual and face to face meetings are scheduled (http://www.congresointernetenelaula.es/congreso.castellano/index.congreso.html) to promote the emergence of these necessary "weak ties" in the community around the repository. More face-toface meetings will probably be necessary to get a strong community around the repository.

To summarize, this service is a key element in the comprehensive strategy for leveraging ICT in education within a national context. In addition, technical features and licenses show that the purpose of "Internet en el Aula", apart from the provision of curriculum orientated educational material, is to seek to develop an active community where users can do more than just retrieve readymade content.

As of the date of writing, the "Internet en el Aula" repository has not been made public, and we are not aware of all features that will be included. Nevertheless, the repository is intended to work as an open library of assured quality content. It is therefore predictable that the number of items will grow and make it necessary to add new features for searching and discriminating along lines of quality and relevance. The following proposals are orientated to these purposes.

\section{Web 2.0 Strategies for Digital Repositories}

We believe that Web 2.0-based participation strategies could increase the engagement of users of learning object repositories. Olcos Roadmap 2012 (Geser, 2007, p. 122) considers that social software tools "are likely to drive innovation in educational practices and resources." We therefore propose the implementation of six well-known Web 2.0 strategies in order to encourage social dynamics within repository communities. These strategies, and the technologies that support them, are commonly used by Web 2.0 companies in order to increase participation and collaboration from their users.

\section{Strategy 1: Clear Authorship and Use License Attribution Systems}

Authorship recognition is a key factor to obtain participation in a community. Free software development communities have shown how a gift economy (a social system in which status is given by how much one shares or gives to their community) works and how a reputation-based gratification system rewards the work of volunteers (Matzan, 2004). In an open digital repository, clear authorship attribution for educative contents (including metacontent: comments, review, favorite, etc.) is a key prerequisite for obtaining ready-to-cooperate participants that aspire to build a reputation by writing quality content. 
On the other hand, copyright and use license must be clearly identified for each piece of content (learning object). The Spanish net of federated repositories is starting its activity with an editorial contribution model, in which different regional administrations will provide content that allows use and modification (under Creative Commons - http://creativecommons.org/ - or similar licenses). Perhaps the same license could be used for all content. If not, use license for each item must be easily identifiable in order to make clear the limits of use and reuse in each case. Of course, CC-like licenses that permit derivative works are the most desirable ones for promoting community and collaborative work.

A collaborative knowledge creation community cannot be established within the bounds of a closed editorial system. An open contribution model is necessary to obtain full benefits from open licenses, as volunteers will be able to develop derivative versions of learning content to be included in the repository.

\section{Strategy 2: Rapid Content Creation Systems}

Social dynamics in communities are strongly affected by the prerequisites for taking part in the system. Secondary School teachers, even if they have deep knowledge about their respective subjects, do not usually have the technical skills (such as animation or programming) that are needed to develop complex digital content. For this reason, multidisciplinary teams have been recommended for the development of LO and LOR (Azpeitia, Monge, \& Ovelar, 2005, pp. 3-4; Margaryan et al., 2007, p. 4).

Repositories should establish dynamics to encourage teachers to participate. In Spain, we have the experience of highly successful communities of educational content development that have arisen around authoring tools such asJClic or Hot Potatoes. Their success in teacher participation has been supported by simple rapid content creation systems (the authoring tools). Consequently, a national repository which expects to use Web 2.0-based dynamics to encourage participation should implement some kind of rapid content creation system, based on templates or any other system that will encourage less technically oriented teachers to collaborate. Rapid creation systems should offer to less technical teachers the opportunity to develop nice-looking learning materials without extensive web design knowledge.

We should consider a problem that may arise if we excessively lower the prerequisites for contributing new contents. The national set of federated repositories might grow but be loaded with low quality contents. Digital information storage would not be a problem. However, the usability of the platform could be in danger, as it gets harder and harder to find specific content because of the proliferation of similar or low-quality content. Two systems could be implemented to counter this problem without having to close off the repository from voluntary contributions:

- Reputation and recommendation systems (see Strategies 5 and 6) could be implemented and used to discriminate between contents of different qualities.

- Repository administrators (Spanish Education Ministry) could award a quality seal for contents that fulfill the requirements that they consider appropriate. Then, repository users could decide to make searches within awarded contents or within all contents, thus granting an optimal user experience.

\section{Strategy 3: Indexable Content for Search Engine (Permalinks)}

Educative contents that are published in our educative platforms (e.g. Moodle) remain, by default, protected by username and password. This is true even if the license allows for free distribution. Even if there is free access (through "guest" user and password), contents are not usually indexed by search engines or easily recommended (through a hyperlink). If the net of federated reposito- 
ries should serve a wide community not limited to teachers or students, it is fundamental to connect it to the rest of the Internet. In order for social dynamics to enter (flows of web traffic, reputation systems, recommendation systems, use of Flickr or Del.icio.us-like tools, etc.), the repository should be easily linkable from external websites. The great majority of online publishing platforms (such as blogs, wikis, other CMSs) use permalink (Wikipedia, 2007) technology to make their contents readily crawlable and indexable for search engines and more understandable for human beings.

The net of Spanish federated repositories should have this kind of technology, because it makes its content accessible from search engines. This way, it will serve a wide community that includes not only teachers and students, but also a broad spectrum of citizens. Moreover, permalink technologies will also favor the linking of contents from other Internet places, which makes reputation (see Strategy 5) and recommendation (see Strategy 6) systems more reliable (through the addition of external information sources).

\section{Strategy 4: Social Tagging Systems}

A lot of international initiatives have concluded that it is necessary to offer descriptive metadata about educational contents, while they have pointed at the same time to the enormous load of work that was needed in order to accomplish that purpose. Social tagging is a very basic form of adding semantic-rich metadata to contents that can help other social dynamics that are proposed in this paper, reputation based systems for instance (Hammond, Hannay, \& Scott, 2005). Social tagging is already being explored by European initiatives like MELT (http://info.melt-project.eu).

On the other hand, the already existing base of quality resources available through Internet could be made available in a clean and contextualized way for repository users through social tagging systems (bookmarking). These external resources would be identified by the community of users in the same way that those of Del.icio.us are. If correctly tagged, resources in other languages could even be added to the repository. External resource tagging is the central point in Intute's (http://www.intute.ac.uk/) or OER's (Open Educational Resources, http://www.oercommons.org/) strategies.

Social tagging and folksonomies have received some criticism. Critics mainly state that tags are ambiguous, overly personalized, and inexact (Guy \& Tonkin, 2006). However, educative context does have a common terminology for talking about its activity, which could be suggested to the user during the tagging process. This way, ambiguity and inexactness could be lessened and the overall quality of this kind of metadata would be increased.

\section{Strategy 5: Reputation Systems for Contents}

Reputation systems (Resnick, Zeckhauser, Friedman, \& Kuwabara, 2000) permit evaluation of the popularity of particular educative content and provide an opportunity to improve the repository search system (displaying more popular contents first). The most widely known reputation systems are Internet Search Engines such as Google, Yahoo! or Microsoft Live. These search engines use implementations of social network analysis theories (Scott, 2000) to determine the relative relevance of Internet web sites and use that ranking to improve their search results, offering relevant content first.

There are many different possible criteria to establish a reputation system for an educational content repository. We propose three criteria and their corresponding indicators to evaluate the social reputation of an educative content within a LOR: 
Use of educative content:

- Total number of visits to the content.

- Total number of downloads of the content, in PDF or other formats, for posterior use (if applicable).

External reputation:

- Number and quality of external links to the content (webs, bloggers, and so on).

- Number of visits that came from Internet (from links of other pages or search engine results).

- Information from other social software tools (like Del.icio.us).

- Number of anonymous comments (non-registered users).

Internal reputation:

- Number and quality of inner hyperlinks (from other contents within repository or from other federated repositories).

- Number of comments or qualified reviews from registered users and system administrators.

- Number of times that the content has been tagged by users (and, therefore, considered worth-keeping).

- Qualification obtained from direct evaluations made by qualified users (registered users and administrators).

These proposed criteria could be used to determine the reputation of particular educational content. If this content reputation system is combined with clear authorship identification, the repository will not only be able to evaluate the reputation of a specific content but also the reputation of a teacher (adding together the reputations of all contents produced by him or her, including metacontents such as comments or reviews).

User reputation ratings are a frequent tool of Web 2.0 applications because they act as a reward for more active (and useful for the system) users, which encourages participation. In a national educative content repository, user reputation rating could be used - in addition to improving the search system and favoring participation socially - as a criterion to reward voluntary contributions from teachers. The reputation obtained from sharing educative contents could also be used as a merit in Primary and Secondary Education Teacher Corps entrance or promotion contests. This is the public corps of Spanish teachers, and it is accessed through participation in public merit contests in which several aspects of applicants' careers are examined (including creation educative contents).

On the other hand, well-implemented reputation systems make it possible to relax the prerequisites for entry to the repository where new content is concerned, because there are criteria for distinguishing between widely used and cited materials and those of lesser quality. Lesser quality (or too specific) learning materials will not be dismissed from the repository because they might possibly offer some value to many teachers. They will just be in the last positions on the search result lists for more generic searches. While accessible through very specific or exhaustive searches, they will not spam more general search results, thus ensuring the usability of the repository for general public. 


\section{Strategy 6: Social Recommendation Systems}

Reputation and tagging systems do not exploit all the possibilities of social dynamics in LOR. Recommendation is another social mechanism that makes it possible to find relevant content and establish a community around a repository. Web 2.0 companies like Amazon (http://www.amazon.com) or MyStrands (http://www.mystrands.com/) have successfully used social recommendation systems to add value to the information they offer. We suggest that a net of federated repositories such as the "Internet en el Aula" project should implement at least two basic recommendation systems:

The first system comes integrated within the repository. Registered users should be able to write and publish reviews about learning content, as Amazon book reviews do, but with an educative approach: e.g. overall evaluations, usage samples, descriptions, or complements to content (links, photos, clarifications, definitions, etc.). Such reviews should have the same reputation attribution systems that are used in the regular educational content of a repository, so that writing a useful review about repository contents actually increases the overall reputation of the teacher who writes it, thereby encouraging participation.

The second recommendation system we are suggesting would be external to the repository application. In order to build an online virtual community, the repository should facilitate a review of its contents by the educative blogosphere. Educational bloggers (or edu-bloggers) constitute a reference for small teacher communities within their area of influence. These bloggers can act as a uniting nexus (the "weak ties") for a national community of teachers that, as already mentioned, is markedly lacking in coherence (there are too many small nuclei, educational centers basically, that are characterized by strong ties). A national repository should implement specific critical functions in order to facilitate participation from the educative blogosphere:

- Easily linkable contents, that is, contents that have permalinks (see Strategy 3).

- RSS feeds that could be personalized by thematic or knowledge areas. Bloggers already know and use this system of subscription and it will allow them to keep up to date with new contents uploaded to repository.

- Trackback technology, that makes it possible to show a link to the blog article(s) that have cited each learning content item. Such a system will return some of the reputation given by the quotation to the quoting blogger, at the same time that content is enriched by references to external sources.

\section{Conclusions}

The provision of educational resources through learning object repositories plays an important role in the development and adoption of ICT in the educational field. The active engagement of users in these systems would leverage their uptake. Furthermore, extending the role of learning object repositories from a storage system to an open platform where users can participate and contribute would benefit innovation in teaching and learning with ICT. To this end, technologies that encourage social dynamics within a repository's community should be implemented. Such technologies work better in an open contribution system than in an editorial system. We have proposed a classification of users and participation tools in order to analyze the contribution models of some key repositories. Our analysis of current educational repositories concludes that, in cases where some features allowed user contributions, not every participation tool implemented obtained a meaningful participation

In addition, we then propose to integrate some well-known Web 2.0 strategies used in successful Internet business within the design process of repositories. These strategies should favor participation and community building around repositories: clear authorship and use license attribution 
systems, rapid content creation systems, social tagging systems, content reputation systems, recommendation systems and easy display of contents in a linkable and search engine friendly way (through permalink technology). We consider that a clever combination of these strategies will improve participation from the repository users and contribute to building community around LOR.

A good start for implementing these strategies is to conceive repositories as multipurpose web Content Management Systems (CMS), like Drupal (drupal.org) or Joomla (www.joomla.org). Open Web2.0-enabled repositories should be able to publish their contents on the Internet in order to receive external links and traffic. External links could be used to implement reliable reputation systems that take into account how many links point to content. General traffic driven through search engines is essential to grow a community that acquires new users.

The Repository 2.0 concept is designed to obtain maximum benefit from user generated content, even if it needs to be sponsored (creating premium quality content) by educational administrations or similar institutions in order to exist. User management should be considered at three levels:

- non-identified users, who only read content and navigate through it with occasional comments.

- identified users (teachers and educators), who contribute to a repository by developing occasional new learning content and by reviewing content generated by other users. They should be driven by gift economies, obtaining reputation from the system by publishing quality content or reviews.

- administrators, who publish high quality content developed by repository sponsors and control inappropriate behaviors between other users. These users are paid and not driven by reputation (gift) economy.

Finally, some interesting research lines around the Repository 2.0 concept remain open:

- Design of algorithms to implement reputation systems in LORs: identifying valid criteria, setting indicators, and weighting them accordingly.

- Development of educational taxonomies to be used for recommendation to users at the social tagging input.

- Studying the success factors of different authoring tools. This information could be used to implement the most successful features in repository authoring and rapid content creation tools

- Studying the factors that make educative content attractive to educational bloggers. Some factors could be: content easy to link, a link back to edu-bloggers' reviews of content in the repository, licenses permitting the publishing of some photos from the educational content in their blogs... This information could be used to design repository features oriented towards attracting attention from the edu-blogging community.

\section{References}

Arthur, C. (2006): What is the 1\% rule? The Guardian. Retrieved June 21, 2007, from http://technology.guardian.co.uk/weekly/story/0,1823959,00.html?gusrc=rss

Azpeitia, I., Monge, S., \& Ovelar, R. (2005): Una Aproximación al Diseño de una Guía de Buenas Prácticas en torno al Paradigma de los Learning Objects. [An aproximation to the design of a Best Practices Guide around Learning Objects Paradigm]. Paper presented at SPDECE 2005 (UOCBarcelona). Retrieved June 26, 2007 from http://www.uoc.edu/symposia/spdece05/pdf/ID14.pdf 
Downes, S. (2004). The learning marketplace. Meaning, metadata and content syndication in the learning object economy. Retrieved May 14, 2007 from http://www.downes.ca/files/book3.htm

Franklin, T., \& Van Harmelen, M. (2007). Web 2.0 for content for learning and teaching in higher education. JISC. Retrieved October 16, 2007 from http://www.jisc.ac.uk/media/documents/programmes/digital repositories/web2-content-learning-andteaching.pdf

Friesen, N. (2006). Connecting collections: An overview of approaches. Retrieved June 12, 2007 from http://www.cancore.ca/protocols en.htm

Granovetter, M. (1973). The Strength of Weak Ties. American Journal of Sociology, 78(6, May), 13601380. Retrieved December 2, 2007 from http://www.stanford.edu/dept/soc/people/mgranovetter/documents/granstrengthweakties.pdf

Gertrudix, M, Álvarez, S., Galisteo, A., Gálvez, M., \& Gértrudix, F. (2007): Acciones de diseño y desarrollo de objetos educativos digitales: programas institucionales. [Actions for design and development of digital educational objects: institutional programs]. In J. Minguillón (coor.), Contenidos educativos en Abierto. RUSC, 4(1). UOC (Universitat Oberta de Catalunya), Barcelona.

Geser, G. (2007). Open educational practices and resources - OLCOS Roadmap 2012. Retrieved May 9 , 2007 from http://www.olcos.org/english/roadmap/

Guy, M., \& Tonkin, E. (2006). Folksonomies. Tidying up tags? D-Lib Magazine, 12(1). Retrieved September 4, 2007 from http://www.dlib.org/dlib/january06/guy/01 guy.html

Hammond, T., Hannay, T., \& Scott, J. (2005). Social bookmarking tools: A general review. D-Lib Magazine, 11(4). Retieved, July 14, 2007 from http://www.dlib.org/dlib/april05/hammond/04hammond.html

The JORUM Team. (2006). Repository Systems Watch. Retrieved July 15, 2007 from http://www.jorum.ac.uk/docs/pdf/Repository_Watch_final_05012006.pdf

LIFE. (2006). Can European teachers find curriculum related digital learning resources? Retrieved May 9, 2007 from http://life.eun.org/ww/en/pub/insight/interoperability/life/reports/curriculum.htm

López, C. (2005). Los repositorios de objetos de aprendizaje como soporte a un entorno e-learning. [Learning objects repositories as platform of e-learning environment.] Dissertation. University of Salamanca. (Director: Francisco José García Peñalvo).

Margaryan, A., Milligan, C., Douglas, P., Littlejohn, A., \& Nicol, D. (2007). Deliverable 10. Recommendations to JISC for future research and development. CD-LOR. Retrieved July 9, 2007 from http://academy.gcal.ac.uk/cd-lor/documents/CDLOR_Final_Recommendations_v1p0.pdf

Matzan, J. (2004): Free software and the gift economy. Retrieved May 9, 2007 from http://www.thejemreport.com/mambo/content/view/125/

McGreal, R. (2004). Learning Objects: A practical definition. International Journal of Instructional Technology and Distance Learning, 1(9). Retrieved July 19, 2007 from http://www.itdl.org/Journal/Sep_04/article02.htm

McGreal, R. (2007). A typology of learning object repositories. Auspace. Retrieved September 9, 2007 from http://hdl.handle.net/2149/1078

Namuth, D., Fritz, S., King, J. \& Boren, A. (2005). Principles of sustainable learning object libraries. Retrieved September 9, 2007 from http://ijklo.org/Volume1/v1p181-196Namuth.pdf

O'Reilly, T. (2005). What is web 2.0: Design patterns and business models for the next generation of software. Online document. Retrieved June 2, 2007 from http:/www.oreillynet.com/pub//a/oreilly/tim/news/2005/09/30/what-is-web-20.html

Resnick, P., Zeckhauser, R., Friedman, E., \& Kuwabara, K. (2000). Reputation systems. Communications of the $A C M, 43(12), 45-48$.

Scott, J. (2000). Social network analysis. London: SAGE Publications. 
Segura, M., Candioti, C., \& Medina, C. J. (2007). "Las TIC en la educación: panorama internacional y situación española" [ICT in education: international oveview and spanish situation] Retrieved December 9, 2007 from http://www.fundacionsantillana.org/Contenidos/Spain/SemanaMonografica/XXII/DocumentoBasico.p df

Thomas, A., \& Rothery, A. (2005). Online repositories for learning materials: The user perspective. Ariadne. Retrieved June 14, 2007 from http://www.ariadne.ac.uk/issue45/thomasrothery/

WIKIPEDIA. (2007). Permalink. Retrieved September 9, 2007 from http://en.wikipedia.org/wiki/Permalink

Wiley, D.A. (2001). Connecting learning objects to instructional design theory: A definition, a metaphor, and a taxonomy. In D. Wiley (Ed.), The instructional use of learning objects. Retrieved July 10, 2007 from http://www.reusability.org/read/chapters/wiley.doc

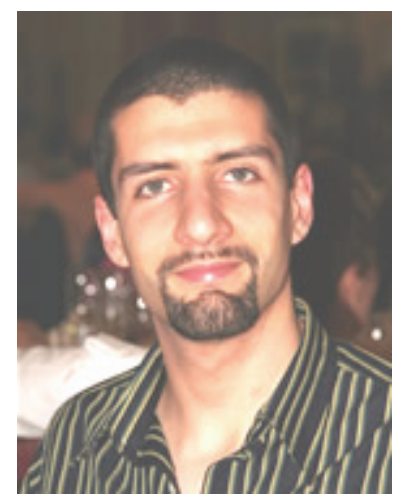

\section{Biographies}

Sergio Monge currently works as an Independent Internet Marketing Consultant. He received a Ph.D. (2007) in Audiovisual Communication and Advertising from the University of the Basque Country. He has been an associate professor at the same university. He is especially interested in communication through web technologies and his areas of interest include social networks, reputation systems, recommendation systems, social tagging, collaborative knowledge generation, visual communication and ICT use in education.

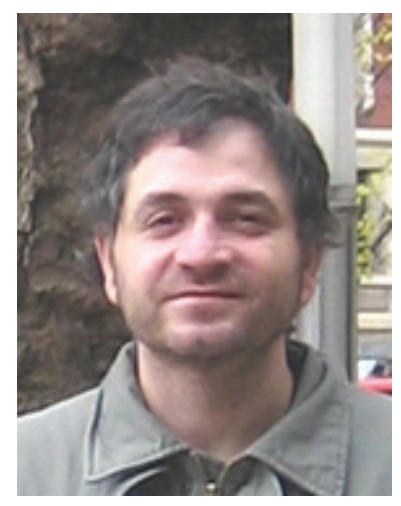

Ramón Ovelar works as an independent e-learning consultant and faculty trainer. He is also member of the GIEL - ELIT research group. $\mathrm{He}$ is a Ph.D student at the University of Alcalá and is researching into how educational technology support sites can make good use of social software.

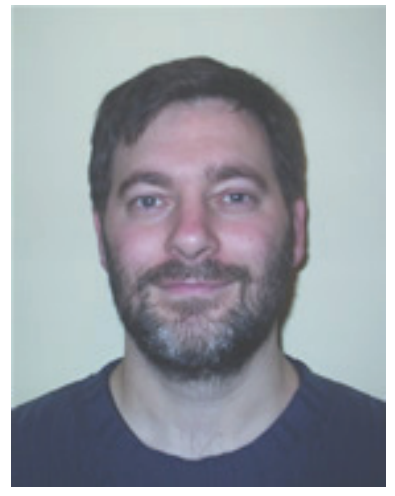

Iker Azpeitia is a professor at the University of the Basque Country. $\mathrm{He}$ is also an active member of the Onekin research group. His main research interests centre around System Engineering, Educational Software and Learning Objects. 